\title{
Efeitos da perda auditiva, escolaridade e idade no processamento temporal de idosos
}

\author{
Effects of age, schooling and hearing loss \\ on temporal processing in elderly
}

Isabela Mizani da Silva Lima(1)

Elisiane Crestani de Miranda-Gonsalez ${ }^{(1)}$

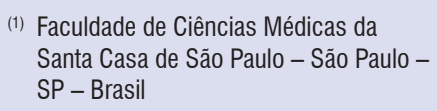

Conflict of interest: non-existent

Received on: July 11,2015

Accepted on: November 12, 2015

Mailing address:

Elisiane Crestani de Miranda-Gonsalez Rua Dr Cesário Motta Jr, 61 - $10^{\circ}$ andar Vila Buarque

São Paulo - SP - Brasil

CEP: 01221-020

E-mail: lisi_miranda@hotmail.com

\section{ABSTRACT}

Purpose: to assess the effect of age, schooling and hearing loss on temporal processing in elderly.

Methods: a total of 30 elderly subjects were assessed comprising 15 with hearing loss (Group 1) and 15 with normal hearing (Group 2). Participants were submitted to audiological assessment, cognitive screening and assessment of temporal processing (resolution and temporal sequencing).

Results: the groups differed for schooling and age, with Group 1 subjects being older $(p=0.024)$ and having less schooling $(p=0.002)$. Group 1 subjects also had higher gaps-in-noise (GIN) detection thresholds and lower GIN detection percentage compared to the performance of Group 2 subjects (GIN Threshold $p=0.002$; GIN \% $p=0.005$ ). Participants from both groups had similar performance for temporal sequencing ability $(p=0.691)$. In this sample, a negative correlation was found between schooling and temporal acuity threshold $(p=0.045)$, i.e. the higher the schooling (in years) the lower the gap detection threshold.

Conclusion: hearing loss had a negative effect on the performance of elderly on temporal resolution tasks. This effect can be more marked in individuals with lower schooling. These same results were not found for the temporal sequencing task.

Keywords: Hearing; Aging; Hearing Loss; Auditory Perceptual Disorders

\section{RESUMO}

Objetivo: avaliar o efeito da perda auditiva, escolaridade e idade no processamento temporal de idosos.

Métodos: foram avaliados 30 idosos, 15 com perda auditiva e baixa escolaridade e (Grupo 1) e 15 com audição normal e maior escolaridade (Grupo 2). Os participantes foram submetidos a avaliação audiológica, triagem cognitiva e avaliação do processamento temporal (resolução e ordenação temporal).

Resultados: nota-se que os além da escolaridade os grupos se diferem em relação a idade, os idosos do Grupo 1 são mais velhos $(p=0,024)$ e menos escolarizados $(p=0.002)$. Os idosos do Grupo 1 apresentaram maior limiar e menor porcentagem de reconhecimento de gaps no ruido quando comparados ao desempenho dos idosos do Grupo 2 (GIN Limiar $p=0,002$; GIN \% $p=0,005$ ). Os participantes de ambos os grupos apresentaram desempenhos similares na habilidade de ordenação temporal $(p=0,691)$. Nesta amostra houve correlação negativa entre escolaridade e limiar de acuidade temporal $(p=0,045)$, ou seja, quanto maior a escolaridade (em anos) menor o limiar de reconhecimento de gaps. Apesar dos grupos serem distintos em relação a faixa etaria, a idade dos idosos não afetou o desempenho para os testes comportamentais do processamento temporal.

Conclusão: Idosos com perda de audição e menor escolaridade apresentam maior prejuizo na habilidade de resolução temporal. Não houve correlação da idade com desempenho nos testes temporais.

Descritores: Audição; Envelhecimento; Perda Auditiva; Transtornos da Percepção Auditiva 


\section{INTRODUCTION}

With aging, there is a decline in sensory and physiological functions - and a hearing deficit is quite common in the elderly ${ }^{1}$. Age-related hearing loss, also known as presbyacusis, is characterized by a drop in hearing function, such as an increase in auditory thresholds and poor frequency resolution ${ }^{2,3}$. The prevalence of age-related hearing loss is expected to rise in coming decades with the population's increasing longevity.

Difficulty in understanding speech in noisy or challenging environments is among the main auditory complaints reported by the elderly, regardless of their hearing sensitivity ${ }^{4}$. The various changes that occur in the auditory system of the elderly can possibly interfere with their ability to efficiently process speech. These difficulties could also be related to a loss in their ability to perform the temporal processing of sounds ${ }^{5}$.

As reported by many researchers, temporal processing is one of the physiological hearing mechanisms that is most affected by aging ${ }^{6-14}$. Grose et al. ${ }^{15}$ and Ajith, Sangamanatha ${ }^{16}$ referiram que com o envelhecimento consider that temporal processing deficits can be observed relatively early in the aging process.

Nevertheless, in most of the studies, interpreting how aging impacts on temporal processing becomes difficult due to the prevalence of age-related hearing loss in the samples studied, especially so when one considers that cochlear lesion reduces the sensitivity to temporal information ${ }^{17-19}$.

As a result, age and hearing loss can be factors leading to temporal processing difficulties. There is yet no consensus in the literature as to whether the determining factor in the elderly having a poor performance of temporal processing is the aging process or peripheral hearing loss. Our hypothesis is that peripheral hearing loss may have a substantial impact on the temporal processing ability in elderly listeners.

This study aimed to investigate the effect of hearing loss in temporal auditory processing for the elderly.

\section{METHODS}

The prospective exploratory study conducted was quantitative in nature. It was approved by the Research Ethics Committee at Santa Casa de São Paulo (CEP 247,182).

When selecting the sample, the following tests were carried out: anamnesis, otoscopy, Mini-Mental State Examination (MMSE) and basic audiological evaluation. Only literate individuals with no history of ear surgery; neurological disorders; exposure to occupational noise/acoustic trauma; systematic musical practice; otological disorders; and chronic use of psychotropic medications were included.

All participants underwent a cognitive screening battery by using the Mini-Mental State Examination test $-\mathrm{MMSE}^{20}$, in order to identify changes in cognitive functions, which might influence the implementation and results of tests for assessing temporal processing. The sample was comprised only of those individuals whose score was equal to or greater than 24 in this assessment. This score was established based on usage suggestions for MMSE in Brazil ${ }^{21}$, according to which scores of 24 are the best cutoff for diagnosing cognitive impairment in senior adults with previous academic record (a sensitivity of $77.8 \%$ and a specificity of $75.4 \%$ ).

Individuals with normal hearing (average hearing thresholds at or below $25 \mathrm{~dB} \mathrm{HL}$ at 500, 1,000 and $2,000 \mathrm{~Hz}$ ) or suffering from mild to moderate sensorineural hearing loss $^{22}$ were included. Noticeably, four ears considered as exhibiting normal hearing showed low- and mid-frequency averages of up to $25 \mathrm{~dB} \mathrm{HL}$ (normal level) and high-frequency $(3,000 \mathrm{~Hz}, 4,000 \mathrm{~Hz}$ and $6,000 \mathrm{~Hz}$ ) averages of $30 \mathrm{~dB} \mathrm{HL}$ (mild level) for the same ear. This aspect does not seem to be decisive in the performance at the tests selected, given that they included white noise as a stimulus, whose spectral magnitude does not change as the temporal pattern is changed, and the pure $1,000-\mathrm{Hz}$ tone with different lengths of time.

For individuals with sensorineural hearing loss, loss configuration should be symmetrical, i.e. hearing loss was considered symmetrical when the difference was equal to or smaller than $10 \mathrm{~dB} \mathrm{HL}$ between the hearing threshold averages (500; 1,000; and 2,000 Hz) observed for the right and left ears.

Subsequently, individuals meeting the aforementioned eligibility criteria were gathered into two groups according to whether or not they had a hearing loss and their level of education. Hence, the groups in this study were thus comprised of: 15 participants aged 60 to 78 years with hearing loss and an average schooling of 6.13 years (Group $1-\mathrm{G} 1$ ); and another 15 participants aged 60 to 75 years with normal hearing thresholds and an average schooling of 9.73 years (Group 2 - G2).

The temporal resolution ability was assessed with the Gap In Noise - GIN - test, with the results being recorded on a compact disc ${ }^{23}$. Track two was used for providing the training and track three for assessment 
under binaural conditions. Each track contains white noise stimuli, six seconds in length each, with a fivesecond interval between stimuli.

Gaps are inserted into white noise at different positions, each having a different duration: 2 ; 3; 4; 5; 6; 8; 10; 12; 15; or 20 ms.

In order to avoid discomfort, the presentation level was $50 \mathrm{dBSL}$ in those individuals with normal hearing and $30 \mathrm{dBSL}$ in the participants with hearing loss.

All participants were given training before taking the test. When the patients could not discriminate the test track, it would be presented to them once again, with the test starting solely after they had recognized at least the gap longest in time duration (20ms). The gap detection threshold was established as being the smallest gap that was perceived in at least $67.7 \%$ of presentations, i.e. four times, since each gap appears six times in each test track. The gap recognition percentage was also determined in relation to all 60 (100\%) existing gaps.

The ability to discriminate and order sound patterns was assessed with the Duration Pattern Test (DPT) (Portuguese acronym for Teste Padrão de Duração) ${ }^{24}$. The test stimuli are sequences of three $1,000-\mathrm{Hz}$ tones with different durations. Thirty sequences containing three tones each were presented, in a binaural fashion, at a $50 \mathrm{dBSL}$ level to individuals with normal hearing and at $30 \mathrm{dBSL}$ to individuals with hearing loss. Participants underwent previous training prior to starting the test, in which they were presented to sequences with three tones each. The test was initiated only after the patients had correctly discriminated and ordered at least four sequences. Correct answers were scored as a percentage.

The data obtained are displayed in terms of descriptive statistics and compared by means of Mann-Whitney and Student's t tests. In all tests conducted, the significance level was set at 0.05 . Statistically significant values were all marked with an asterisk [*] superscript.

\section{RESULTS}

In this study, the sample consists of two groups of elderly, which were distinguished by the presence or absence of hearing loss, with G1 consisting of elderly with sensorineural hearing loss (SHL) and G2 comprised of elderly people with normal hearing. Symmetry between the tritonal averages of the right ear and the left ear can be observed in the participants of both groups, all of whom had MMSE scores above 24 , as previously established in the eligibility criteria for participating in this study. It is worth mentioning that he groups differ significantly with regard to level of education and age (Table 1): 4.2 life years $(p=0.024)$ and 3.6 years of schooling $(p=0.002)$ (Table 2$)$.

Table 1. Descriptive statistics for: Age (years); Level of education (years of schooling); and tritonal averages of the Right Ear and Left Ears in both groups

\begin{tabular}{lccccccc}
\hline Variable & Group & N & Average & $\begin{array}{c}\text { Standard } \\
\text { deviation }\end{array}$ & Minimum & Median & Maximum \\
\hline \multirow{2}{*}{ Age } & 1 & 15 & 69.8 & 4.9 & 60 & 71 & 78 \\
& 2 & 15 & 65.6 & 4.8 & 60 & 64 & 75 \\
\hline \multirow{2}{*}{ Level of education } & 1 & 15 & 6.13 & 2.0 & 1 & 5 & 7 \\
& 2 & 15 & 9.73 & 2.8 & 8 & 10 & 15 \\
\hline \multirow{2}{*}{ Tritonal average RE } & 1 & 15 & 40.3 & 8.3 & 25 & 40 & 50 \\
& 2 & 15 & 13.3 & 4 & 10 & 15 & 25 \\
\multirow{2}{*}{ Tritonal average LE } & 1 & 15 & 40.6 & 9.2 & 30 & 40 & 50 \\
\multirow{2}{*}{ MMSE } & 2 & 15 & 12.6 & 5,6 & 5 & 10 & 25 \\
\hline
\end{tabular}

Group 1 = elderly participants with hearing loss; Group 2 = elderly participants with normal hearing; LE = Left Ear; RE = Right Ear; $F=$ female; $M=$ male. 
Table 2. Descriptive statistics for age (Mann-Whitney test) and level of education (Student's t-test) in each group

\begin{tabular}{lccccccc}
\hline Variable & Group & Average & Median & SD & Minimum & Maximum & p-value \\
\hline \multirow{2}{*}{ Age } & 1 & 69.8 & 71.0 & 4.9 & 60.0 & 78.0 & \multirow{2}{*}{0.024} \\
\hline \multirow{2}{*}{ Level of education } & 2 & 65.6 & 64.0 & 4.8 & 60.0 & 75.0 & \\
\hline
\end{tabular}

Group 1 = elderly participants with hearing loss; Group 2 = elderly participants with normal hearing; $\mathrm{SD}=$ standard deviation; $\mathrm{p}$-value $<0.05$.

When descriptively evaluating the results from the temporal tests according to the variable presence or absence of hearing loss (G1XG2), it was observed that the subjects in $\mathrm{G} 1$ had a higher threshold and a lower percentage of hits at the GIN test hits than did the elderly in G2 (GIN Threshold $p=0.002$; GIN\% $p=0.005$ ). Conversely, at the temporal ordering test, DPT (Duration Pattern Test), elderly individuals with hearing loss exhibited similar performance when compared to the elderly with normal hearing $(p=0.691)$ (Table 3).

In the face of these results, some questions arose as to the influence from the participants' level of education and age on their performance at the temporal processing tests. There was observed a negative correlation between the participants' level of education and their performance on the GIN threshold, i.e. the higher the level of education (in years), the smaller the gap recognition threshold (in $\mathrm{ms})(p=0.045)$. Nevertheless, the performance of the elderly at GIN\% $(p=0.067)$ and DPT $(p=0.914)$ was not influenced by the level of education. Despite the fact that the two groups differ as to participants' age, this variable did not affect their performance at behavioral temporal processing tests (Table 4).

Table 3. Descriptive statistics for Threshold GIN test; GIN \%; and Duration Pattern Test in each group (Mann-Whitney test)

\begin{tabular}{lccccccc}
\hline & Group & Average & Median & SD & Minimum & Maximum & p-value \\
\hline \multirow{2}{*}{ Threshold GIN } & 1 & 8.67 & 8 & 1.7 & 6 & 12 & \multirow{2}{*}{$0.003^{*}$} \\
\hline \multirow{2}{*}{ GIN \% } & 2 & 6.53 & 6 & 1.6 & 5 & 10 & \\
\hline \multirow{2}{*}{ DPT } & 1 & 50.1 & 51.6 & 10.7 & 30 & 66.6 & \multirow{2}{*}{$0.005^{\star}$} \\
\hline
\end{tabular}

Group 1 = elderly participants with hearing loss; Group 2 = elderly participants with normal hearing; $\mathrm{SD}=$ standard deviation; p-value $<0.05$; DPT = Duration Pattern Test.

Table 4. Correlation coefficients between temporal tests and level of education; and the age in the overall sample (Student's t-test)

\begin{tabular}{lcc}
\hline & Level of education & Age \\
\hline GIN \% & $p=0.067$ & $p=0.239$ \\
Threshold GIN & $p=-0.045^{\star}$ & $p=-0.292$ \\
DPT & $p=0.914$ & $p=-0.170$ \\
\hline
\end{tabular}

GIN = gap

DPT $=$ Duration Pattern Test 


\section{DISCUSSION}

The overall sample was composed of elderly people with and without hearing loss. It was found that the elderly with hearing loss (G1) are older and less educated than the elderly with normal hearing (G2).

The difference in age and level of education between the groups is attributed to the different sites/ environments used for sample selection. Initially, the senior individuals were randomly selected from the health care services at the Speech Therapy Clinic - Clinical Audiology Unit, located in the São Paulo Hospital School, State of São Paulo (care provided by the Unified Health System, Sistema Único de Saúde - SUS). The elderly from Group 1, with hearing loss, were easily selected at this clinic; nonetheless, a small number of patients had no hearing loss. In order to complete Group 2, a partnership was established with a group of Senior Citizens who performed activities in the same area of the city and from which elderly individuals without hearing loss were then recruited.

Not only are the individuals who participate in activities promoted by the Senior Citizen groups mostly younger elderly, whose age ranges from 60-69 years, but they are also individuals with a higher levels of education, with a large proportion of them having finished high school or college ${ }^{25}$. The level of educational found in the elderly with no hearing loss constitutes a factor that differentiates this group with regard to the level of education generally observed among the elderly population. When considering the elderly in the population as a whole, today's elderly cohort comes from a time when access to education was precarious.

The elderly who attend Senior Citizen groups are cognitively in better shape due to the fact that they have greater access to intellectual and physical activities. This investigation included MMSE and all seniors who did not score the minimum marks at this screening were excluded from the study. Still, it is well known that, in order to better understand the influence of cognitive factors on the behavioral assessment of the auditory processing, more extensive studies are required, involving scales that make it possible to identify subtle deficits in specific areas of cognitive function - especially those related to memory and information processing speed.

Another important factor is the fact that the incidence and severity of hearing loss is significantly associated with aging ${ }^{26-29}$. Hence, elderly individuals with hearing loss (G1) are expected to be older than those in the group without hearing loss (G2).
The ability of the auditory system to process sound temporal information is fundamental to understanding speech $^{16,18,20,30,31}$. The gap detection threshold, i.e. the ability to detect the shortest duration of a silent interval inserted into a sound is commonly used for studying the auditory temporal resolution. Behavioral studies have demonstrated that, in senior individuals, gap detection thresholds are higher than those observed in young adults.

In the present study, the analysis of the performance of the elderly with normal peripheral hearing sensitivity (G2) revealed that the average gap recognition percentage was lower and the temporal acuity threshold higher than previously published findings in adults ${ }^{13,32-36}$. The same trend can be observed in the ability to discriminate sound patterns, measured with DPT, elderly without hearing loss could recognize $61 \%$ of gaps in noise, a percentage that is lower than that reported in the literature for adults with normal hearing ${ }^{32,35}$. In comparing these data with the present study, it can be inferred that age negatively affects temporal processing.

When checking the behavioral auditory responses in the temporal processing of the elderly, with regard to the variable hearing loss (G1xG2), it can be observed that the elderly with hearing loss (G1) had significantly worse scores at both the temporal acuity threshold analysis and gap recognition percentage when compared to seniors with normal hearing (G2), i.e. the presence of hearing loss resulted in a lesser gap recognition percentage and a higher temporal acuity threshold in the elderly.

According to Henry, Heinz ${ }^{17}$ and Füllgrabe37, sensorineural hearing loss diminishes the sensitivity to the sound's temporal structure, which thus compromises the performance of the elderly in temporal resolution tasks. The sensitivity to the temporal structure of the acoustic signals seems to be important for the successful identification of speech under complex listening conditions ${ }^{18}$. This result helps to explain speech perception problems in hearing-impaired elderly that commonly arise under noisy conditions.

In this study, there was no difference in the performance of elderly people with or without hearing loss in the sound pattern discrimination task (DPT). These findings corroborate the study conducted by Mesquita and Pereira ${ }^{38}$, in which elderly people with up to moderate hearing loss showed DPT performance similar to that of seniors with normal hearing. 
In this study, there was observed a linear correlation between level of education and temporal acuity threshold at GIN (p-value 0.045), i.e. with increasing educational level, there is a decrease in the temporal acuity threshold. Pinheiro et al. ${ }^{39}$ inferred that the level of education has an influence on the tasks involving participation of the hearing abilities of temporal resolution and ordering.

The strong effect of education can be explained by the interaction of inferential abilities with other cognitive functions such as working memory, vocabulary and knowledge of the world. The level of education is positively correlated with the ability to perform highly demanding cognitive tasks. Such difference can also be explained by the well-known interaction between the number of years of schooling and performance involving several cognitive-linguistic tasks, such as episodic memory, attention, reading, vocabulary and executive functions.

Despite the fact that the two groups differ as to participants' age, this variable did not affect their performance at behavioral temporal processing tests. It is worth mentioning that when we say that age has not influenced this ability, we are actually referring to the age variation observed in this study (60-78 years), given that we have already addressed the differences observed between our results and those from studies with young adults.

The results demonstrate that the presence of hearing loss coupled to aging impairs the performance of the elderly at temporal resolution tasks. This difference can be larger still in individuals with a low level of education, which thus leads to greater difficulty distinguishing the sounds of speech and capture the differences between acoustic signals in everyday life. These findings are relevant and should be considered in the assessment and rehabilitation of the hearing-impaired elderly.

\section{CONCLUSION}

Elderly individuals with hearing loss and a lesser level of education have impaired temporal resolution ability. Among seniors, there was no correlation between age and their performance at temporal tests.

\section{REFERENCES}

1. Ciorba A, Bianchini C, Pelucchi S, Pastore A. The impact of hearing loss on the quality of life of elderly adults. Clin Inter Aging. 2012;7:159-63.
2. Li-Korotky HS. Age-related hearing loss: quality of care for quality of life. Gerontologist. 2012;52(2)265-71.

3. Stam M, Smits C, Twisk JW, Lemke U, Festen JM, Kramer SE. Deterioration of Speech Recognition Ability Over a Period of 5 Years in Adults Aged 18 to 70 Years: Results of the Dutch Online Speech-inNoise Test. Ear \& Hearing. 2015;36(3):e129-37.

4. Schoof $T$, Rosen S. The role of auditory and cognitive factors in understanding speech in noise by normal-hearing older listeners. Front Aging Neurosc. 2014;6:307.

5. Palmer SB, Musiek FE. Electrophysiological gap detection thresholds: effects of age and comparison with a behavioral measure. J Am Acad Audiol. 2014;25(10):999-1007.

6. Snell K. Age-related changes in temporal gap detection. J Acoust Soc Am. 1997;101(4):2214-20.

7. Schneider B, Speranza F, Pichora-Fuller MK. Age-related Changes in Temporal Resolution: Envelope and Intensity Effects. Can J Exp Psychol. 1998;52(4):184-91.

8. He NJ, Horwitz AR, Dubno JR, Mills JH. Psychometric functions for gap detection in noise measured from young and aged subjects. J Acoust Soc Am. 1999;106(2):966-78.

9. Gordon-Salant S, Yeni-Komshian G, Fitzgibbons PJ. The role of temporal cues in word identification by younger and older adults: Effects of sentence context. J Acoust Soc Am. 2008;124(5):3249-60.

10. Lister J, Koehnke JD, Besing JM. Binaural gap duration discrimination in listeners with impaired hearing and normal hearing. Ear Hear. 2000;21(2):141-50.

11. Bertoli S, Smurzynski J, Probst R. Temporal resolution in young and elderly subjects as measured by mismatch negativity and a psychoacoustic gap detection task. Clin Neurophysiol. 2002;113(3):396-406.

12. Kołodziejczyk I, Szelsg E. Auditory perception of temporal order in centenarians, in comparison with young and elderly subjects. Acta Neurobiol Exp. 2008;68(3):373-81.

13. Liporaci FD. Estudo do Processamento Auditivo Temporal (resolução e ordenação) em idosos [Dissertação]. Rio de Janeiro (RJ): Universidade Veiga de Almeida; 2009.

14. Fitzgibbons PJ, Gordon-Salant S. Age-related differences in discrimination of temporal 
intervals in accented tone sequences. Hear Res. 2010;264(1-2):41-7.

15. Grose JH, Hall JW, Buss E. Temporal processing deficits in the pre-senescent auditory system. J Acoust Soc Am. 2006;119(4):2305-15.

16. Ajith KU, Sangamanatha AV. Temporal processing abilities across different age groups. J Am Acad Audiol. 2011;22(1):5-12.

17. Henry KS, Heinz MG. Diminished temporal coding with sensorineural hearing loss emerges in background noise. Nat neurosci. 2012;15:1362-4.

18. Moore BCJ. Auditory Processing of Temporal Fine Structure: Effects of Age and Hearing Loss. Singapore: World Scientific; 2014.

19. Gallun FJ, McMillan GP, Molis MR, Kampel SD, Dann SM, Konrad-Martin DL. Relating age and hearing loss to monaural, bilateral, and binaural temporal sensitivity. Front Neurosci. 2014;8:172.

20. Bertolucci PHF, Brucki SMD, Campacci SR, Juliano Y. O Mini-exame do estado mental em uma população geral. Arq Neuropsiquiatr. 1994;52:1-17.

21. Osvaldo P. Mini exame dos estado mental e o diagnóstico de demência no Brasil. Arq. NeuroPsiquiatr: 1998;56(3B):605-12 .

22. Lloyd LL, Kaplan H. Audiometric interpretation: a manual o basic audiometry. Baltimore: University Park Press, 1978.

23. Musiek FE, Shinn JB, Jirsa R, Bamiou DE, Baran JA, Zaida E. GIN (Gaps-In- Noise) test performance in subjects with confirmed central auditory nervous system involvement. Ear Hear. 2005;26(6):608-18.

24. Musiek FE, Baran JA, Pinheiro ML. Duration Pattern recognition in normal subjects and patients with cerebral and cochlear lesions. Audiology. 1990;29(6):304-13.

25. Barreto KML, Carvalho EMF, Falcão IV, Lessa FJD, Leite VMM. Perfil sócio-epidemiológico demográfico das mulheres idosas da Universidade Aberta à Terceira Idade no estado de Pernambuco. Rev Bras Saude Mater Infant. 2003;3(3):339-54.

26. Sousa MGC, Russo ICP. Audição e percepção da perda auditiva em idosos. Rev Soc Bras Fonoaudiol. 2009;14(2):241-6.

27. Baraldi GS, Almeida LC, Borges ACC. Evolução da perda auditiva no decorrer do envelhecimento. Braz J Otorhinolaryngol. 2007;73(1):64-70.

28. Liporaci FD, Frota SMMC. Resolução temporal auditiva em idosos. Rev Soc Bras Fonoaudiol. 2010;15(4):533-9.
29. Lin FR, Thorpe R, Gordon-Salant S, Ferrucci L. Hearing loss prevalence and risk factors among older adults in the United States. J A Biol Sci and Med Sci. 2011;66(5):582-90.

30. Silveira KM, Borges AC, Pereira LD. Memória, interação e integração em adultos e idosos de diferentes níveis ocupacionais avaliados pelos testes da avaliação simplificada e teste dicótico de dígitos. Distúrb Comun. 2004;16(3):313-22.

31. Lister JJ, Roberts RA. Effects of age and hearing loss on gap detection and the precedence effect: narrow-band stimuli. J. Speech Lang Hear Res. 2005;48(2):482-93.

32. Samelli AG, Schochat E. Estudo da vantagem da orelha direita em teste de detecção de gap. Braz J Otorhinolaryngol. 2008;74(2):235-40.

33. Zaidan E, Garcia AP, Tedesco MLF, Baran JA. Desempenho de adultos jovens normais em dois testes de resolução temporal. Pró-fono $\mathrm{R}$ Atual Cient. 2008;20(1):19-24.

34. Rabelo CM. Avaliação eletrofisiológica e comportamental do processamento temporal. [Mestrado]. São Paulo (SP): Faculdade de Medicina, Universidade de São Paulo; 2009.

35. Helfer KS, Vargo M. Speech Recognition and Temporal Processing in Middle-Aged Women. J Am Acad Audiol. 2009;20(4):264-71.

36. Dias TLL. Resolução temporal e cognição no idoso saudável [Dissertação]. São Paulo (SP): Universidade Federal de São Paulo; 2010.

37. Fullgrabe C. Age-dependent changes in temporal-fine-structure processing in the absence os peripheral hearing loss. Am $\mathrm{J}$ Audiol. 2013;22(2):313-5.

38. Mesquita LG, Pereira LD. Processamento temporal em idosos: o efeito da habilidade de resolução temporal em tarefas de ordenação de série de sons. Rev CEFAC. 2013;15(5):1163-9.

39. Pinheiro MMS, Dias KZ, Pereira LD. Acoustic stimulation effect on temporal processing skills in elderly subjects before and after hearing AID fitting. Braz J Otorhinolaryngol. 2012;78(4):9-16. 